\title{
Effects of the provision of solid feeds enriched with protein or nonprotein nitrogen on veal calf growth, welfare, and slaughter performance
}

\author{
M. Brscic, ${ }^{*}$ P. Prevedello, ${ }^{*}$ A. L. Stefani, † G. Cozzi, ${ }^{*}$ and F. Gottardo*1 \\ *Department of Animal Medicine, Production and Health, University of Padova, Viale dell'Università 16, 35020 Legnaro (PD), Italy \\ †Istituto Zooprofilattico Sperimentale delle Venezie, Viale dell'Università 10, 35020 Legnaro (PD), Italy
}

\begin{abstract}
The study compared the effects of enriching a basic solid feed mixture made of corn grain and straw with a protein source (extruded pea) or with urea on growth, health, behavior, and carcass quality of veal calves. Seventy-nine calves, divided according to their initial body weight $(59.8 \pm 6.9 \mathrm{~kg})$ into 3 groups ( 5 pens of 5 or 6 animals per group), were allotted to 1 of 3 experimental feeding treatments: milk replacer plus an 85:15 (as-fed basis) mixture of corn grain and wheat straw (CGS); milk replacer plus a 72:15:13 mixture of corn grain, wheat straw, and extruded pea (CGS-EP); or milk replacer plus an 83.3:16:0.7 mixture of corn grain, wheat straw, and urea (CGS-U). All feeding treatments were targeted to provide $140 \mathrm{~kg}$ of dry matter (DM)/ calf of solid feed during the 201-d fattening cycle, and the greater crude protein content of the mixtures supplemented with protein or urea was balanced by restricting to $96 \%$ the daily amount of milk replacer delivered to CGS. Results did not differ among feeding treatments for average daily gain or solid feed intake but, net of meal refusal events, the average daily intake of milk replacer was $1.73,1.66$, and $1.60 \mathrm{~kg}$ of DM/ calf for CGS, CGS-EP, and CGS-U, respectively. The overall mean hemoglobin values from samples taken at d 11, 40, 83, 126, and 196 were lower for CGS-U calves $(9.1 \pm 0.2 \mathrm{~g} / \mathrm{dL})$ compared with CGS $(9.8 \pm 0.2 \mathrm{~g} / \mathrm{dL})$, whereas those of CGS-EP were intermediate $(9.4 \pm 0.2$ $\mathrm{g} / \mathrm{dL}$ ). Behavioral observations showed a frequency of oral stereotypes $<1.2 \%$ for all feeding treatments. Longer eating and chewing or ruminating time was recorded for CGS-U calves compared with CGS and CGS-EP calves. All carcasses had satisfactory color for the veal market and none of the carcass traits were affected by the feeding treatments. The proportions of tongues and lungs with signs of lesions, forestomach development, abomasal lesions, and rumen plaques did not differ among feeding treatments. Hyperkeratinization of ru-
\end{abstract}

Received October 17, 2013.

Accepted March 22, 2014.

${ }^{1}$ Corresponding author: flaviana.gottardo@unipd.it men papillae was observed only in CGS-U calves with a prevalence of $11.3 \%$. Based on these findings, providing a corn grain and straw solid feed mixture enriched with extruded pea or urea was an effective strategy to reduce milk replacer consumption, lowering total feeding cost per calf by 3.0 to $3.4 \%$ and 6.9 to $7.2 \%$, respectively. This economic advantage was supported by the lack of detrimental effects on calf growth performance, behavior, and carcass quality. However, the occurrence of rumen papillae hyperkeratosis may raise some concerns about the use of urea.

Key words: veal calf, solid feed, nitrogen source, welfare

\section{INTRODUCTION}

Legislation on animal welfare in Europe made mandatory the provision of solid feed to milk-fed veal calves but without specific guidelines regarding their type and composition (European Council Directive 2008/119/ EC, 2008; European Union, 2009). In recent years, the veal calf industry has faced a sharp increase in production costs driven by the global increase in the price of skim milk powder. This has spurred farmers to develop new feeding plans using large amounts of solid feeds with different compositions as partial substitutes for the expensive milk replacers. Cereal grains were preferentially used for their low iron content, which allowed production of pale-colored meat. However, several studies proved that, despite promoting fast gain (Suárez et al., 2006), cereal grains were not the ideal option for calf welfare because of their negative effects on gastrointestinal health and behavior (Cozzi et al., 2002a; Mattiello et al., 2002). A suggested alternative was partial replacement of the grains with a roughage source, which has been shown to promote chewing and reduce oral stereotypies (Cozzi et al., 2002b) and decrease rumen mucosa hyperkeratosis and plaques (Brscic et al., 2011). Recently, Prevedello et al. (2012) studied the effect of introducing a protein source in the solid feed, along with a proportional reduction of the amount of milk replacer. Results showed that this feeding strategy, in which the chemical composition of the solid feed 
was closer to that of diets for preweaned calves, was effective in improving veal calf health and welfare and reducing milk replacer meal refusals and rumen mucosa alterations. Aiming at reducing the cost of feed, diets for fattening cattle commonly combine feed proteins with small amounts of nonprotein nitrogen sources such as urea (Duff et al., 2003; Zinn et al., 2003). So far, this strategy has not been tested on veal calves, but the use of urea might be particularly interesting as an iron-free source of nitrogen that should not have a direct effect on meat color.

To make a scientific contribution to the definition of a suitable solid feed for veal calves, the present study compared the effects on growth, health, behavior, and carcass quality of a basic mixture made of corn grain and straw provided alone or enriched with a protein source (extruded pea) or with urea.

\section{MATERIALS AND METHODS}

\section{Animals and Housing}

This study was carried out using 81 male Polish Frisian veal calves reared in a commercial veal calf farm located in the Veneto region (Italy) in compliance with the legislation on their protection [European Council Directive 2008/119/EC, 2008 (European Union, 2009); Decreto Legislativo 2011/126 (Ministero della Salute, 2011)]. Two out of 81 calves were excluded early from the study because they did not habituate to the bucket milk feeding and were, therefore, moved from the trial pens to the weaning pen of the farm. The remaining 79 calves, weighing $60.4 \mathrm{~kg} \pm 4.1( \pm \mathrm{SD})$ of $\mathrm{BW}$ upon the arrival at the farm, were allotted according to their initial BW to 3 experimental groups in 5 contiguous group pens within treatment of 5 or 6 animals located within the same barn. All pens had fully slatted wooden floors and allowed a space of $1.8 \mathrm{~m}^{2} /$ calf.

\section{Feeding Treatments and Management}

After an adaptation period of $35 \mathrm{~d}$ in which all calves received the same feeding plan of milk replacer and an 85:15 mixture (as-fed basis) of corn grain and 5-cm chopped wheat straw (Table 1 ), the 3 groups of calves were randomly assigned to 1 of the following feeding plans: (1) milk replacer plus the basic solid mixture provided during the adaptation period (CGS); (2) milk replacer plus a 72:15:13 mixture (as-fed basis) of corn grain, 5-cm chopped wheat straw, and extruded pea, respectively (CGS-EP); and (3) milk replacer plus an 83.3:16:0.7 mixture (as-fed basis) of corn grain, 5-cm chopped wheat straw, and urea, respectively (CGS-U). Details of the experimental diets are given in Table 1 .

Regardless of treatment group, all calves received the same milk replacers. A starter milk replacer (Spraymes Rosso 50, Sloten Italia, Crema, Italy) containing $50 \%$ skim milk powder was provided during the adaptation period of $35 \mathrm{~d}$. During the subsequent transition period of $20 \mathrm{~d}$, calves were gradually shifted to a grower-finisher milk replacer (Spraymes Verde Unico Energy 30, Sloten Italia) made with 30\% skim milk powder (Table 1). The daily amount of milk replacer powder and its concentration in the liquid diet were progressively increased during the fattening period from 193 to 2,800 g of $\mathrm{DM} /$ calf and from 4 to $18 \%$, respectively. The daily concentration of milk replacer was the same across feeding treatments but, to provide isonitrogenous diets, the greater $\mathrm{N}$ content of the solid mixtures supplemented with protein or urea was balanced by restricting to $96 \%$

Table 1. Chemical composition (mean $\pm \mathrm{SD}$ ) of the feeds delivered to veal calves during the fattening cycle

\begin{tabular}{|c|c|c|c|c|c|}
\hline \multirow[b]{2}{*}{ Item } & \multicolumn{2}{|c|}{ Milk replacer } & \multicolumn{3}{|c|}{ Solid feed (as-fed basis) } \\
\hline & Starter $^{1}$ & $\begin{array}{l}\text { Grower/ } \\
\text { finisher }^{2}\end{array}$ & $\begin{array}{l}\text { Corn grain + } \\
\text { straw }(85: 15)\end{array}$ & $\begin{array}{c}\text { Corn grain }+ \\
\text { straw }+ \text { extruded pea } \\
(72: 15: 13)\end{array}$ & $\begin{aligned} & \text { Corn grain } \\
&+ \text { straw + urea } \\
&(83.3: 16: 0.7)\end{aligned}$ \\
\hline DM, $\%$ & $96.5 \pm 0.2$ & $96.5 \pm 0.4$ & $88.3 \pm 0.6$ & $88.8 \pm 0.5$ & $88.4 \pm 0.7$ \\
\hline $\mathrm{CP}, \%$ of $\mathrm{DM}$ & $23.8 \pm 0.6$ & $22.1 \pm 1.4$ & $7.6 \pm 0.1$ & $10.0 \pm 0.1$ & $9.6 \pm 0.6$ \\
\hline Ether extract, \% of DM & $18.7 \pm 0.3$ & $22.8 \pm 1.0$ & $3.5 \pm 0.4$ & $3.5 \pm 0.4$ & $3.5 \pm 0.4$ \\
\hline $\mathrm{NFC},{ }^{3} \%$ of $\mathrm{DM}$ & $49.9 \pm 0.4$ & $46.9 \pm 0.9$ & $64.2 \pm 1.8$ & $61.0 \pm 1.5$ & $61.6 \pm 2.2$ \\
\hline Iron, $\mathrm{mg} / \mathrm{kg}$ & $5.6 \pm 0.8$ & $7.9 \pm 1.2$ & $29.9 \pm 14.3$ & $35.9 \pm 14.1$ & $30.6 \pm 15.1$ \\
\hline Gross energy, MJ $/ \mathrm{kg}$ of $\mathrm{DM}$ & 20.6 & 21.3 & 18.8 & 18.7 & 18.8 \\
\hline $\mathrm{UFV},{ }^{4} / \mathrm{kg}$ of $\mathrm{DM}$ & & & 1.14 & 1.13 & 1.12 \\
\hline
\end{tabular}

${ }^{1}$ Ingredient composition of starter milk replacer: skim milk powder, whey powder, vegetable and animal lipid sources, starch, wheat protein, and premix.

${ }^{2}$ Ingredient composition of grower/finisher milk replacer: whey powder, skim milk powder, vegetable and animal lipid sources, starch, and premix.

${ }^{3} \mathrm{NFC}$ calculated as $100-(\mathrm{NDF}+\mathrm{CP}+$ ether extract + ash $)$.

${ }^{4}$ Unité fourragère viande (76.1852 MJ) estimated using reference values proposed by INRA (1988) for solid feed ingredients. 
the daily amount of milk replacer delivered in the CGS treatment. The daily ration of milk replacer was delivered in 2 equal meals at 0700 and $1700 \mathrm{~h}$ in individual buckets equipped with a teat. The 3 experimental feeding plans were designed to supply at least $140 \mathrm{~kg}$ of $\mathrm{DM} /$ calf from the solid feed throughout the fattening cycle, which lasted $201 \mathrm{~d}$. To reach this target amount, solid feed offered to the calves of all treatments was increased weekly from the initial $45 \mathrm{~g}$ of $\mathrm{DM} /$ calf per day up to $1,330 \mathrm{~g}$ of $\mathrm{DM} /$ calf per day at the end of the fattening. In each pen, solid feeds were distributed twice a day in a common manger immediately after the milk replacer meal. To limit competition among pen-mates, calves were individually separated by headlocks until most of the solid feed was consumed (approximately 30 min). Calves had free access to drinking water through a nipple-drinker.

Samples of milk replacers and solid feeds were collected monthly during the fattening cycle and they were subsequently analyzed for DM, CP, ether extract, ash, and iron content according to the procedures of AOAC (1990). Feed samples were also analyzed for NDF content as proposed by Van Soest et al. (1991) and the NFC content was calculated as $100-(\mathrm{NDF}+$ $\mathrm{CP}+$ ether extract + ash). Chemical composition of milk replacers and solid feeds provided during fattening is reported in Table 1.

\section{In Vivo Experimental Measurements}

Growth Performance. The fattening cycle lasted $201 \mathrm{~d}$ and calves' individual BW were measured at the beginning, at d 126, and at the end of the cycle to calculate individual ADG. Individual intake of milk replacer was recorded daily by the difference between the distributed and the leftover amounts, whereas average daily intake of solid feed was calculated for each group pen by dividing the difference between delivered and leftover amounts for the number of pen-mates. Feed efficiency was calculated as a ratio between ADG and average daily intake.

Blood Parameters. Individual blood samples were collected at d 11, 40, 83, 126, and 196 of the fattening by the farm veterinarian. Samples were taken from the jugular vein immediately after the morning feeding using Vacutainer tubes containing lithium heparin (Becton, Dickinson and Co., Franklin Lakes, NJ) to measure urea and bilirubin concentrations. All plasma samples were analyzed on the Hitachi 911 (Hoffmann-La Roche Ltd., Basel, Switzerland) at $37^{\circ} \mathrm{C}$ using the analytical methods reported by Cozzi et al. (2011). Hemoglobin levels were measured using the automated Coulter analyzer (model STKS; Instrumentation Laboratories, Lexington, MA) on samples collected in Venosafe tubes containing $\mathrm{K}_{3}$ EDTA (Terumo Europe N.V., Leuven, Belgium).

Health Status. General health status of the calves was monitored by recording medical treatments and milk replacer meal refusal events. Medical treatments to recover from a given health problem were recorded by the stockman and they were expressed as ratio between days of treatment and days of fattening (Prevedello et al., 2012). Milk replacer meal refusal events were assessed by recording the number of calves drinking less than half of the milk delivered in a given meal. Data were expressed as the ratio between refused milk meals and total meals offered (Cozzi et al., 2002b). Calves at high risk of being anemic at a given hemoglobin check were injected with iron dextran (Endofer, Fatro S.p.A., Ozzano Emilia, Italy).

Behavior. Four observation sessions of calves' behavior were carried out at d 53,91, 133, and 186 of fattening. At each observation session, calves were observed from $1 \mathrm{~h}$ before to $3 \mathrm{~h}$ after the morning meal by 2 trained observers using the scan-sampling technique (Martin and Bateson, 1993) with a 5-min interval. At each scan, observers recorded the number of calves per pen that were standing or lying, and whether calves were eating solid feed, chewing-ruminating, or performing oral stereotypies. According to Maekawa et al. (2002), postural and feeding behavioral data were then transformed from absolute frequencies of events per number of scans in minutes, assuming that each activity was performed during the entire scan interval.

\section{Postmortem Experimental Measurements}

All calves were slaughtered at the same slaughterhouse on d 202. Carcasses were weighed to calculate individual dressing percentage and graded by a trained expert for conformation (EUROP score) and fatness according to European Council Regulation 1026/91 (European Union, 1991). A meat market expert visually evaluated the compliance of carcass color to the market standard. Moreover, instrumental carcass color was measured $2 \mathrm{~h}$ after slaughter in the brisket area using a CR-100 Chroma Meter (Minolta Camera, Osaka, Japan) equipped with a 5.0-mm aperture and illuminant C. At the slaughterhouse, organs including tongue, lungs, liver, rumen, and abomasum were inspected, keeping records of each individual calf. Tongues were visually inspected after their excision from the head, and the presence of lesions was recorded as binary presence or absence. Lungs were scored according to the protocol described by Leruste et al. (2012) and classified on a 4 -point scale from 0 for no signs of pneumonia to 3 for severe pneumonia. Liver was visually evaluated for hepatic lipidosis, looking at signs of friable, enlarged, 
and yellow fatty livers as binary presence or absence (West, 1997). Reticulorumen was weighed after being opened, emptied, and rinsed in running water. Rumen development was scored as described by Brscic et al. (2011) on a 4-point scale from 1 for low development to 4 for full development. Presence (yes or no) of papillary epithelial hyperkeratinization or plaques on the rumen wall was also recorded (Brscic et al., 2011). Lesions on the mucosa of the abomasal torus pyloricus were counted from 0 (absence of lesions) to a censored maximum of 4 (presence of 4 or more lesions) within each of the following 3 size classes: small $=$ lesions $<0.5 \mathrm{~cm}$ in diameter, medium $=0.5$ to $1 \mathrm{~cm}$ diameter lesions, and large $=$ lesions $>1 \mathrm{~cm}$ in diameter. To estimate the overall damage in the abomasa, a weighted lesions mean score was then calculated as follows: [(number of small lesions $\times 1)+($ number of medium lesions $\times 2)$ + (number of large lesions $\times 3$ )], and it ranged from 0 for no lesions to a censored maximum of 24 (Brscic et al., 2011).

\section{Statistical Analysis}

Pen was the experimental unit for all variables, and data regarding growth performance, carcass color and empty reticulorumen weight were statistically processed using a linear model (PROC GLM, SAS Institute Inc., Cary, NC) that considered the effect of the feeding treatment. Feed intake and blood variables were processed using a mixed model (PROC MIXED, SAS Institute Inc.) with feeding treatment, day of fattening (repeated option), the interaction of feeding treatment $\times$ day of fattening, and the random effect of pen within treatment. Behavioral data were processed by a mixed model considering the effects of feeding treatment, day of fattening (repeated option), time from feeding, and their interactions as fixed effects and the random effect of pen within treatment. Soundness of the models was assessed graphically according to the normal distribution, homoscedasticity, and identical distribution of the residuals. Categorical and ordinal data regarding carcass EUROP and fatness scores, rumen development, and abomasal lesion scores were analyzed using the Kruskal-Wallis nonparametric test with PROC NPAR1WAY (SAS Institute Inc.), considering the feeding treatment effect. Data obtained from inspection of organs at the slaughterhouse were expressed as proportions of organs with a given score or with a given problem over the total number of examined organs per feeding treatment. Statistical analyses of variables expressed as proportions were performed using the $\chi^{2}$ tests with the Marascuilo procedure to verify their association with a given feeding treatment.
When this association was significant $(P<0.05)$, odds ratios and $95 \%$ CI were calculated.

\section{RESULTS AND DISCUSSION}

Calf growth performance in terms of ADG and feed efficiency was not affected by feeding treatment (Table 2 ). The total DMI was significantly higher for CGS calves compared with CGS-U calves, with CGS-EP calves being intermediate. This result was not due to different intake of the solid fraction of the diets but simply the consequence of the experimental design of the study that, to provide isonitrogenous diets across treatments, counterbalanced the higher $\mathrm{CP}$ of the solid feeds enriched with a nitrogen source by lowering the daily amount of milk replacer. Compared with the CGS diet, CGS-EP and CGS-U decreased by 0.07 and 0.13 $\mathrm{kg} /$ calf, respectively, the average daily amount of milk replacer DM. Regardless of the treatment, the feeding plan was targeted to provide a total amount of $140 \mathrm{~kg}$ of $\mathrm{DM} /$ calf of solid feed in combination with the milk replacer. According to the Italian feedstuffs market (Borsa Merci di Modena, 2014), the cost of the basic 85:15 mixture of corn grain and straw of the CGS treatment was US $\$ 38 /$ calf and the inclusion of extruded peas or urea increased the cost per calf of the solid feeding by 16 and $1 \%$, respectively. This higher cost of the solids was compensated by the reduction of the amount of milk powder, which is the most expensive feed ingredient for veal calves. In this study, the cost of the milk replacer was US $\$ 245 / 100 \mathrm{~kg}$, and the economic advantage of the 2 alternative feeding strategies compared with CGS was estimated to be about 3.1 and $7.1 \%$ for CGS-EP and CGS-U, respectively. In a wider scenario, the expected advantage of the same feeding strategy (milk replacer $+140 \mathrm{~kg}$ of DM from solid feed) is supposed to range between 3.0 and $3.4 \%$ for CGS-EP and between 6.9 and $7.2 \%$ for CGS-U, considering a range of prices for the milk replacer from US\$165/100 $\mathrm{kg}$ (all whey protein powder) to US $\$ 290 / 100 \mathrm{~kg}(50 \%$ skim milk powder).

Despite the large quantity of solid feed, veal calves drank the daily amount of milk replacer offered with a very low proportion of refusal events throughout the study (Table 3). The dietary iron provided by all feeding treatments was adequate to prevent anemia, and none of the calves was injected with iron dextran throughout the fattening cycle. Treatment $\times$ day of fattening interaction did not affect blood hemoglobin concentration $(P=0.68)$. As expected for veal calves (Reece and Hotchkiss, 1987), hemoglobin decreased over time $(P<$ 0.001) (Figure 1a). Regarding the feeding treatment effect $(P=0.03)$, hemoglobin values were lower for CGS- 
Table 2. Growth performance, feed intake, and feed efficiency of veal calves receiving different feeding treatments during the 201-d fattening cycle (LSM \pm SEM)

\begin{tabular}{|c|c|c|c|c|}
\hline \multirow[b]{2}{*}{ Item } & \multicolumn{3}{|c|}{ Feeding treatment ${ }^{1}$} & \multirow[b]{2}{*}{$P$-value } \\
\hline & CGS & CGS-EP & CGS-U & \\
\hline Pens, ${ }^{2}$ no. & 5 & 5 & 5 & \\
\hline Days of fattening, no. & 201 & 201 & 201 & \\
\hline \multicolumn{5}{|l|}{ Live weight,${ }^{3} \mathrm{~kg}$} \\
\hline Initial & $60.4 \pm 0.8$ & $60.5 \pm 0.8$ & $60.3 \pm 0.8$ & 0.99 \\
\hline d 126 & $196.5 \pm 2.3$ & $192.8 \pm 2.3$ & $194.9 \pm 2.3$ & 0.55 \\
\hline Final & $291.8 \pm 4.9$ & $285.8 \pm 4.9$ & $292.2 \pm 4.9$ & 0.60 \\
\hline \multicolumn{5}{|l|}{$\mathrm{ADG},{ }^{3} \mathrm{~g}$} \\
\hline $0-126 \mathrm{~d}$ & $1,184 \pm 20$ & $1,150 \pm 20$ & $1,170 \pm 20$ & 0.50 \\
\hline $127-201 \mathrm{~d}$ & $1,270 \pm 41$ & $1,240 \pm 41$ & $1,298 \pm 41$ & 0.62 \\
\hline $0-201 \mathrm{~d}$ & $1,252 \pm 29$ & $1,224 \pm 29$ & $1,258 \pm 29$ & 0.69 \\
\hline \multicolumn{5}{|c|}{ Feed consumption, ${ }^{3} \mathrm{~kg}$ of DM/d } \\
\hline Milk replacer & $1.73^{\mathrm{a}} \pm 0.03$ & $1.66^{\mathrm{ab}} \pm 0.03$ & $1.60^{\mathrm{b}} \pm 0.03$ & 0.05 \\
\hline Solid feed & $0.71 \pm 0.00$ & $0.71 \pm 0.00$ & $0.71 \pm 0.00$ & \\
\hline Total & $2.49^{\mathrm{a}} \pm 0.03$ & $2.42^{\mathrm{ab}} \pm 0.03$ & $2.36^{\mathrm{b}} \pm 0.03$ & 0.05 \\
\hline Feed efficiency ${ }^{3}$ & $0.50 \pm 0.01$ & $0.50 \pm 0.01$ & $0.53 \pm 0.01$ & 0.09 \\
\hline \multicolumn{5}{|l|}{ CP intake, ${ }^{3} \mathrm{~g} / \mathrm{d}$} \\
\hline From milk replacer & $385.0^{\mathrm{a}} \pm 6.9$ & $369.6^{\mathrm{ab}} \pm 6.9$ & $357.6^{\mathrm{b}} \pm 6.9$ & 0.05 \\
\hline From solid feeds & $53.7 \pm 0.0$ & $71.1 \pm 0.0$ & $67.9 \pm 0.0$ & \\
\hline Total & $442.5 \pm 6.9$ & $445.8 \pm 6.9$ & $430.4 \pm 6.9$ & 0.29 \\
\hline \multicolumn{5}{|l|}{ Iron intake ${ }^{3} \mathrm{mg} / \mathrm{d}$} \\
\hline From milk replacer & $13.7^{\mathrm{a}} \pm 0.2$ & $13.1^{\mathrm{ab}} \pm 0.2$ & $12.7^{\mathrm{b}} \pm 0.2$ & 0.05 \\
\hline From solid feeds & $21.1 \pm 0.0$ & $25.5 \pm 0.0$ & $21.7 \pm 0.0$ & \\
\hline Total & $36.3^{\mathrm{b}} \pm 0.2$ & $40.5^{\mathrm{a}} \pm 0.2$ & $35.9^{\mathrm{b}} \pm 0.2$ & $<0.001$ \\
\hline
\end{tabular}

$\overline{\mathrm{a}, \mathrm{b}}$ Least squares means within a row with different superscripts differ for the reported $P$-value.

${ }^{1}$ CGS $=$ milk replacer $+85: 15$ mixture (as-fed basis) of corn grain and straw; CGS-EP $=$ milk replacer + 72:15:13 mixture of corn grain, straw, and extruded pea; CGS-U = milk replacer + 83.3:16:0.7 mixture of corn grain, straw, and urea.

${ }^{2}$ Each pen housed 5 to 6 calves for a total of 26 CGS, 27 CGS-EP, and 26 CGS-U calves.

${ }^{3}$ Data analyzed by pen (experimental unit) and expressed as a mean per animal.

U calves $(9.1 \pm 0.2 \mathrm{~g} / \mathrm{dL})$ compared with CGS $(9.8$ $\pm 0.2 \mathrm{~g} / \mathrm{dL} ; P=0.02)$, whereas CGS-EP calves had intermediate levels $(9.4 \pm 0.2 \mathrm{~g} / \mathrm{dL})$. In this regard, we could hypothesize that the hemoglobin values of CGS calves reflected the larger intake of iron from the milk replacer rather than the total iron intake (Table 2). Previous studies (Cozzi et al., 2002a; Prevedello et al., 2012) indicated that iron from milk replacer is more bioavailable for calf metabolism than that from solid feeds, in which the micromineral is bound to the NDF fraction.

Indirect bilirubin mean values (Figure 1b) were always below the pathological threshold indicative of hepatic dysfunction (Lumsden et al., 1980). Plasma urea concentrations were not affected by the feeding treatments $(P=0.28)$ and always fell within the ranges of normality reported for female Holstein calves of same age interval (Lumsden et al., 1980). A day of fattening

Table 3. Proportions, odds ratio, and 95\% CI of days of treatment for health disorders and proportions of milk replacer meal refusals in veal calves receiving different feeding treatments during the 201-d fattening cycle

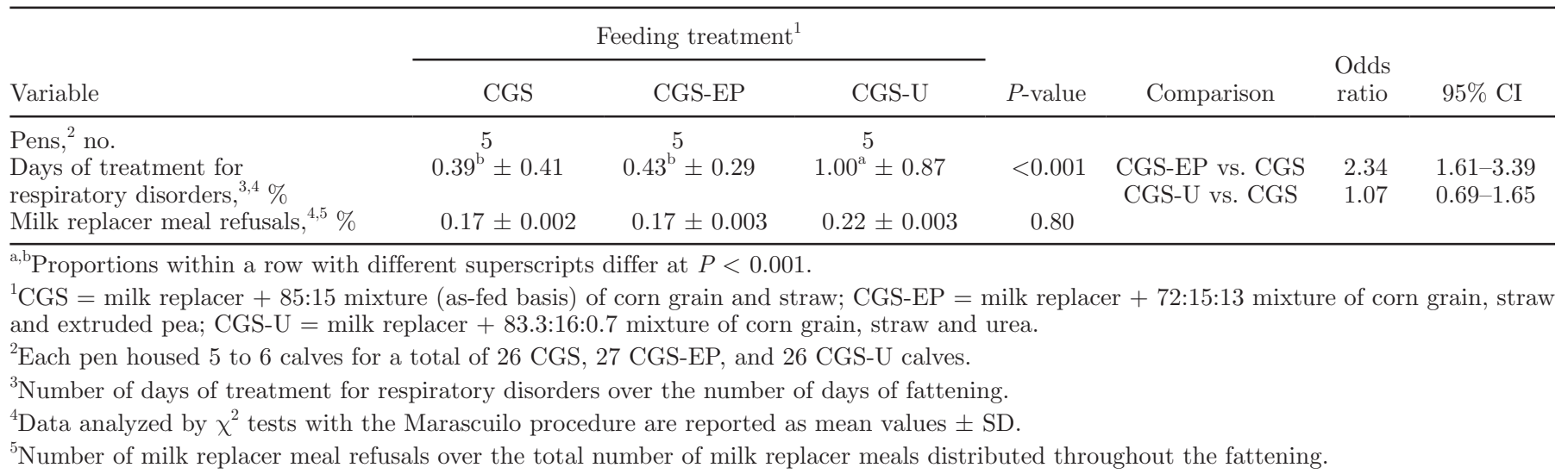



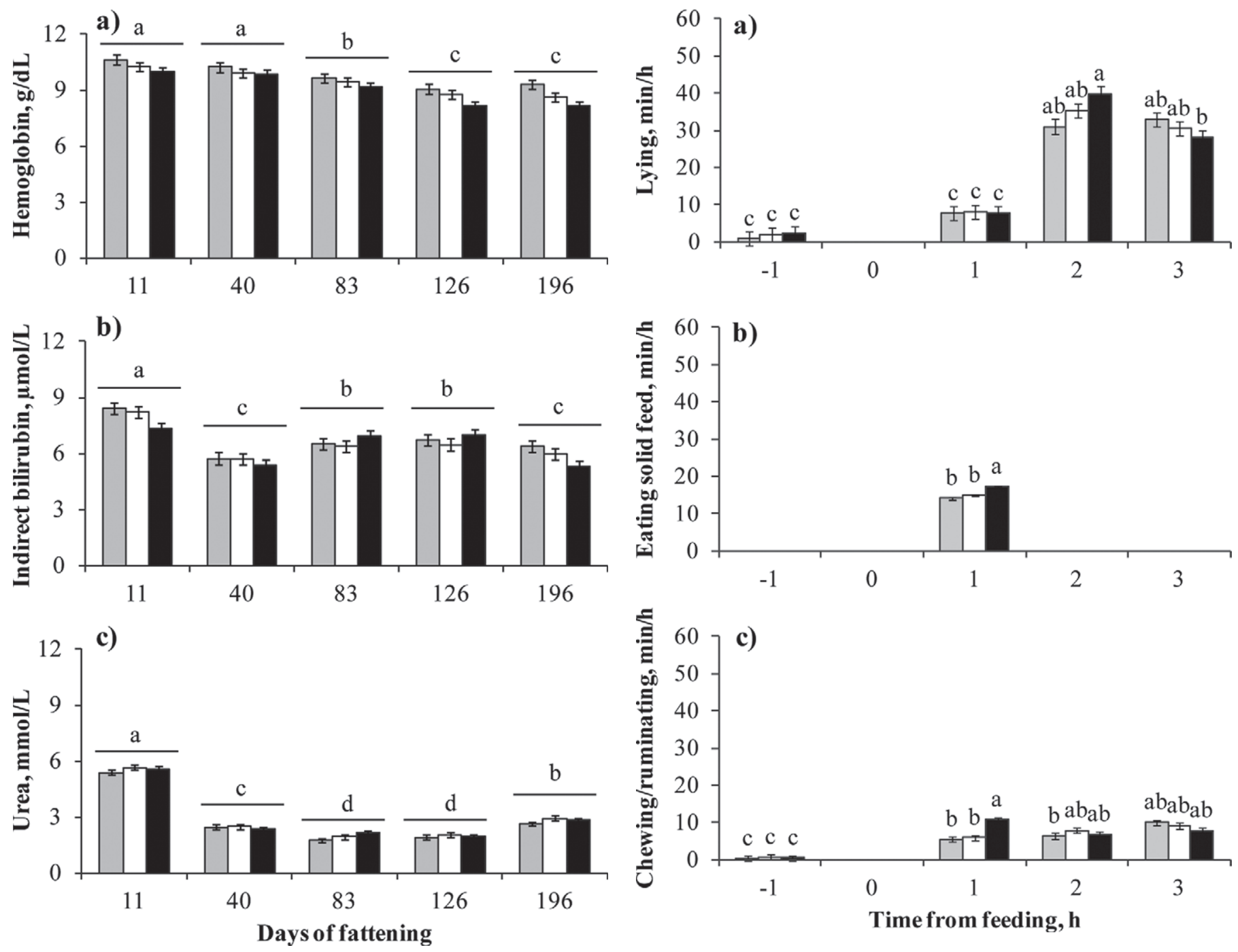

Figure 1. Concentration (LSM \pm SEM) of (a) hemoglobin ( $/ \mathrm{dL}$ ), (b) indirect bilirubin $(\mu \mathrm{mol} / \mathrm{L})$, and $(\mathrm{c})$ urea $(\mathrm{mmol} / \mathrm{L})$ of calves fed CGS $=$ milk replacer $+85: 15$ mixture (as-fed basis) of corn grain and straw (gray bars); CGS-EP $=$ milk replacer $+72: 15: 13$ mixture of corn grain, straw, and extruded pea (white bars); or CGS-U = milk replacer + 83.3:16:0.7 mixture of corn grain, straw, and urea (black bars) at d $11,40,83,126$, and 196 of fattening. Within blood parameter, different letters differ for the effect of the day of fattening $(P<0.05)$.

effect $(P<0.001)$ was observed for urea, with a marked decrease from d 11 to 40 of fattening (Figure 1c). The increase in protein requirement to support calf growth and the onset of rumen development promoted by the intake of solid feeds (Van Soest, 1991) are possible explanations for this trend.

Behavioral observations of calves around feeding time revealed a treatment $x$ time from feeding interaction for lying $(P=0.03)$. As expected, calves were lying more frequently 2 and $3 \mathrm{~h}$ after the meal, with only CGS-U calves behaving differently within this time interval (Figure 2a). Veal calves crave solid feeds and,

Figure 2. Duration (LSM \pm SEM) of (a) lying, (b) eating solid feed, and (c) chewing or ruminating expressed in minutes/hour of calves fed CGS $=$ milk replacer $+85: 15$ mixture (as-fed basis) of corn grain and straw (gray bars); CGS-EP $=$ milk replacer $+72: 15: 13$ mixture of corn grain, straw, and extruded pea (white bars); or CGS-U $=$ milk replacer $+83.3: 16: 0.7$ mixture of corn grain, straw, and urea (black bars) $1 \mathrm{~h}$ before, and 1,2 , and $3 \mathrm{~h}$ after the morning milk replacer and solid feed meal delivery. Within behavior, different letters differ for the effect of treatment $\times$ time from feeding interaction $(P$ $<0.05)$.

as observed by Prevedello et al. (2012), they consumed solid food within $1 \mathrm{~h}$ from delivery (Figure $2 \mathrm{~b}$ ). Calves fed CGS-U had a longer eating time, which could be due to the bitter taste of urea (Nombekela et al., 1994). The taste of urea could also explain the greater chewing observed in CGS-U calves during the ingestive activity in the first hour from feed delivery compared with CGS and CGS-EP calves (treatment $\times$ time from feeding interaction; $P=0.001$; Figure 2c). The frequency of oral stereotypies averaged $1.21 \% \pm 0.45$, and it was similar among feeding treatments $(P=0.50)$. The oc- 
Table 4. Prevalence of lesions or alterations on tongue, lungs, liver, rumen, and abomasum, and empty reticulorumen weight of veal calves receiving different feeding treatments

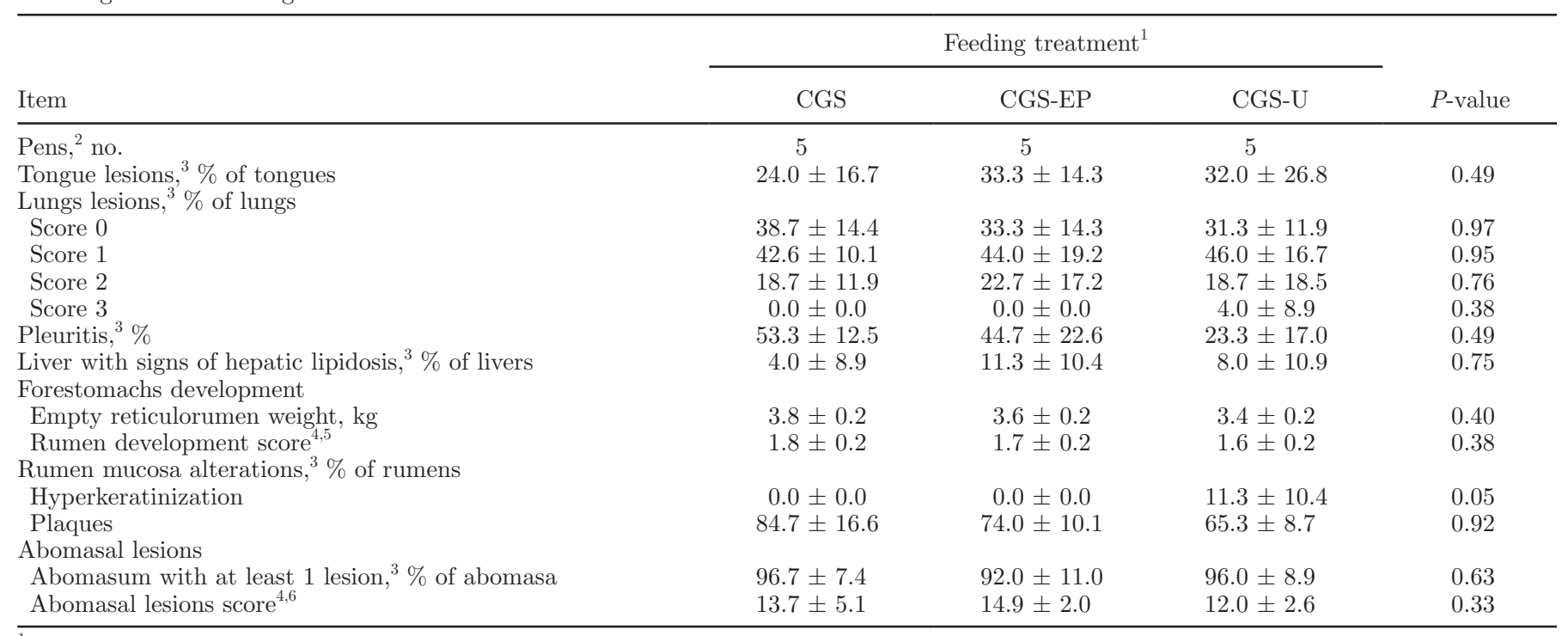

${ }^{1}$ CGS $=$ milk replacer $+85: 15$ mixture (as-fed basis) of corn grain and straw; CGS-EP $=$ milk replacer + 72:15:13 mixture of corn grain, straw, and extruded pea; CGS-U = milk replacer + 83.3:16:0.7 mixture of corn grain, straw, and urea.

${ }^{2}$ Each pen housed 5 to 6 calves for a total of 26 CGS, 27 CGS-EP, and 26 CGS-U calves.

${ }^{3}$ Data analyzed by $\chi^{2}$ tests with the Marascuilo procedure with pen as experimental unit and expressed as frequency of cases per treatment \pm SD.

${ }^{4}$ Data analyzed by Kruskal-Wallis and Mann-Whitney tests with pen as experimental unit and expressed as mean per animal \pm SD.

${ }^{5} 1=$ low developed to $4=$ fully developed rumen.

${ }^{6}$ Score weighted according to the number of lesions (from 0 to maximum of 4 , censored) and size category $($ small $=<0.5 \mathrm{~cm} ;$ medium $=0.5-1$ $\mathrm{cm}$; large $=>1 \mathrm{~cm})$ calculated as $[($ no. of small lesions $\times 1)+($ no. of medium lesions $\times 2)+($ no. of large lesions $\times 3)]$; score ranged from 0 for no lesions to a censored maximum of 24 .

Table 5. Slaughter performance (LSM \pm SEM) and carcass evaluation of veal calves receiving different feeding treatments

\begin{tabular}{|c|c|c|c|c|}
\hline \multirow[b]{2}{*}{ Item } & \multicolumn{3}{|c|}{ Feeding treatment ${ }^{1}$} & \multirow[b]{2}{*}{$P$-value } \\
\hline & CGS & CGS-EP & CGS-U & \\
\hline Pens, ${ }^{2}$ no. & 5 & 5 & 5 & \\
\hline Carcass weight, ${ }^{3} \mathrm{~kg}$ & $183.8 \pm 4.4$ & $178.0 \pm 4.4$ & $181.5 \pm 4.4$ & 0.66 \\
\hline Dressing $^{3}$ & $0.63 \pm 0.01$ & $0.62 \pm 0.01$ & $0.62 \pm 0.01$ & 0.81 \\
\hline \multicolumn{5}{|l|}{ Carcass evaluation } \\
\hline EUROP score 4,5 & $3.80 \pm 0.20$ & $3.81 \pm 0.18$ & $3.78 \pm 0.18$ & 0.92 \\
\hline Fatness score ${ }^{4,6}$ & $2.00 \pm 0.00$ & $1.96 \pm 0.09$ & $2.04 \pm 0.09$ & 0.25 \\
\hline \multicolumn{5}{|l|}{ Carcass color ${ }^{3,7}$} \\
\hline Lightness $\left(\mathrm{L}^{*}\right)$ & $38.0 \pm 1.2$ & $36.0 \pm 1.2$ & $36.6 \pm 1.2$ & 0.50 \\
\hline Redness $\left(\mathrm{a}^{*}\right)$ & $8.8 \pm 0.4$ & $9.8 \pm 0.4$ & $9.4 \pm 0.4$ & 0.35 \\
\hline Yellowness ( $\mathrm{b}^{*}$ ) & $7.4 \pm 0.4$ & $8.0 \pm 0.4$ & $8.3 \pm 0.4$ & 0.24 \\
\hline
\end{tabular}

${ }^{1}$ CGS $=$ milk replacer $+85: 15$ mixture (as-fed basis) of corn grain and straw; CGS-EP $=$ milk replacer + 72:15:13 mixture of corn grain, straw, and extruded pea; CGS-U = milk replacer + 83.3:16:0.7 mixture of corn grain, straw, and urea.

${ }^{2}$ Each pen housed 5 to 6 calves for a total of 26 CGS, 27 CGS-EP, and 26 CGS-U calves.

${ }^{3}$ Data analyzed by pen (experimental unit) and expressed as a mean per animal.

${ }^{4}$ Data analyzed by Kruskal-Wallis and Mann-Whitney tests with pen as experimental unit and expressed as mean per animal $\pm \mathrm{SD}$.

${ }^{5} 1=$ poor to $5=$ excellent.

${ }^{6} 1=$ minimum to $3=$ maximum

${ }^{7} \mathrm{~L}^{*}$ values measure darkness to lightness (greater $\mathrm{L}^{*}$ value indicates a lighter color); $\mathrm{a}^{*}$ values measure redness (greater $\mathrm{a}^{*}$ value indicates a redder color); and $\mathrm{b}^{*}$ values measure yellowness (greater $\mathrm{b}^{*}$ value indicates a more yellow color). 
currence of abnormal oral behaviors in veal calves is decreased by provision of solid feeds (Mattiello et al., 2002; Cozzi et al., 2009) and the results of the present study support this finding.

Regardless of feeding treatment, postmortem inspection at the slaughterhouse showed that more than $20 \%$ of the tongues had at least 1 lesion (Table 4). As observed by Karren et al. (1994) in beef cattle, mouth ulcers might have been caused by a mechanical friction of roughages. However, other factors such as chewing on fencing may have predisposed calves to the occurrence of tongues lesions. Regarding respiratory disorders, a higher number of days of treatment was observed in CGS-U calves (Table 3). It is difficult to directly associate these results to the provision of urea when considering the findings of Duff et al. (2003) that showed no effect of supplementing urea up to $1 \%$ of total dietary $\mathrm{DM}$ on the occurrence of bovine respiratory disease in receiving beef cattle. This assumption is supported by the similar proportions of lungs with lesions $(P=0.38)$ and pleuritis $(P=0.49)$ recorded postmortem among treatments (Table 4 ).

Forestomach development, abomasal lesions, and rumen plaques were not affected by feeding treatments, whereas the hyperkeratinization of rumen papillae was observed only in CGS-U calves (Table 5). This latter result was unexpected because all feeding treatments included similar amounts of straw, which, through its abrasive effect on rumen papillae, has shown to be a preventive factor for hyperkeratosis in young calves (Beharka et al., 1998). The lack of information regarding the effect of urea on rumen parameters such as $\mathrm{pH}$ or VFA profile of a preruminant calf does not allow us to directly associate rumen papillae hyperkeratosis with the provision of urea. However, considering that CGS-U calves ate more slowly, we can hypothesize that they had more time to perform feed selection. Among pen-mates, dominant and voracious eaters could have preferentially addressed their intake toward corn grain, which is one of the main risk factors for the development of rumen hyperkeratosis (Brscic et al., 2011). Signs of hepatic lipidosis were detected in a small proportion of livers that did not differ according to feeding treatments (Table 5). Carcass weight, EUROP and fatness scores, and dressing percentage were not affected by feeding treatments (Table 5). All carcasses had a satisfactory color for the veal market and the outcomes of the instrumental color evaluation were similar among treatments.

\section{CONCLUSIONS}

The provision of solid mixtures supplemented with a protein source (extruded pea) or with urea at a target level of $140 \mathrm{~kg}$ of $\mathrm{DM} /$ calf was an effective strategy to allow a relevant reduction of the total consumption of milk replacer. The economic advantage of these innovative feeding plans compared with the use of the basic CGS diet was estimated to be 3.0 to $3.4 \%$ and 6.9 to $7.2 \%$ with extruded pea or urea, respectively, considering the use of a wide range of milk replacers from an all-whey protein powder to 50\% skim milk powder. Further support came from the lack of any detrimental effects on either calf growth performance or carcass quality. However, the occurrence of rumen papillae hyperkeratosis may raise some concern about the use of urea.

\section{ACKNOWLEDGMENTS}

The authors thank Veneto Region (Italy) for granting the SPAI.Vit. project. A special thanks to Barbara Contiero (Department of Animal Medicine, Production and Health, University of Padova, Italy) for the precious statistical support.

\section{REFERENCES}

AOAC. 1990. Official Methods of Analysis. 15th ed. Assoc. Off. Anal. Chem., Arlington, VA.

Beharka, A. A., T. G. Nagaraja, J. L. Morrill, G. A. Kennedy, and R. D. Klemm. 1998. Effects of form of the diet on anatomical, microbial, and fermentative development of the rumen of neonatal calves. J. Dairy Sci. 81:1946-1955.

Borsa Merci di Modena. 2014. Wholesale price list of the week for foodstuffs and feedstuffs. Accessed Jan. 14, 2014. http://www. borsamercimodena.it.

Brscic, M., L. F. M. Heutinck, M. Wolthuis-Fillerup, N. Stockhofe, B. Engel, E. K. Visser, F. Gottardo, E. A. M. Bokkers, B. J. Lensink, G. Cozzi, and C. G. van Reenen. 2011. Prevalence of gastrointestinal disorders recorded at post-mortem inspection in white veal calves and associated risk factors. J. Dairy Sci. 94:853-863.

Cozzi, G., M. Brscic, and F. Gottardo. 2009. Main critical factors affecting the welfare of beef cattle and veal calves raised under intensive rearing systems in Italy: A review. Ital. J. Anim. Sci. 8:67-80.

Cozzi, G., F. Gottardo, S. Mattiello, E. Canali, E. Scanziani, M. Verga, and I. Andrighetto. 2002a. The provision of solid feeds to veal calves: I. Growth performance, forestomach development, carcass and meat quality. J. Anim. Sci. 80:357-366.

Cozzi, G., F. Gottardo, F. Mutinelli, B. Contiero, G. Fregolent, S. Segato, and I. Andrighetto. 2002b. Growth performance, behaviour, forestomach development and meat quality of veal calves provided with barley grain or ground wheat straw for welfare purpose. Ital. J. Anim. Sci. 1:113-126.

Cozzi, G., L. Ravarotto, F. Gottardo, A. L. Stefani, B. Contiero, L. Moro, M. Brscic, and P. Dalvit. 2011. Reference values for blood parameters in Holstein dairy cows: Effects of parity, stage of lactation and season of production. J. Dairy Sci. 94:3895-3901.

Duff, G. C., K. J. Malcolm-Callis, M. L. Galyean, and D. A. Walker. 2003. Effects of dietary urea concentration on performance and health of receiving cattle and performance and carcass characteristics of finishing cattle. Can. J. Anim. Sci. 83:569-575.

European Union. 2009. European Council Directive 2008/119/EC 2008: Laying down minimum standards for the protection of calves (codified version). Off. J. L 010.

European Union. 1991. European Council Regulation 91/1026: Community scale for the classification of carcass of adult bovine animals. 2985. Office of Official Publications, Luxemburg.

INRA (Institut National de la Recherche Agronomique). 1988. Alimentation des Bovins, Ovins et Caprins. INRA, Paris, France. 
Karren, D. B., L. A. Goonewardene, and J. A. Bradley. 1994. The effect of feed type on mouth lesions in slaughter cattle. Can. J. Anim. Sci. 74:571-573.

Leruste, H., M. Brscic, L. F. M. Heutinck, E. K. Visser, M. WolthuisFillerup, E. A. M. Bokkers, N. Stockhofe-Zurwieden, G. Cozzi, F. Gottardo, B. J. Lensink, and C. G. van Reenen. 2012. The relationship between clinical signs of respiratory system disorders and lung lesions at slaughter in veal calves. Prev. Vet. Med. 105:93-100.

Lumsden, J. H., K. Mullen, and R. Rowe. 1980. Hematology and biochemistry reference values for female Holstein cattle. Can. J. Comp. Med. 44:24-31.

Maekawa, M., K. A. Beauchemin, and D. A. Christensen. 2002. Chewing activity, saliva production, and ruminal $\mathrm{pH}$ of primiparous and multiparous lactating dairy cows. J. Dairy Sci. 85:1176-1182.

Martin, P., and P. Bateson. 1993. Measuring Behaviour: An Introductory Guide. Cambridge University Press, Cambridge, UK.

Mattiello, S., E. Canali, V. Ferrante, M. Caniatti, F. Gottardo, G. Cozzi, I. Andrighetto, and M. Verga. 2002. The provision of solid feeds to veal calves: II. Behaviour, physiology and abomasal damage. J. Anim. Sci. 80:367-375.

Ministero della Salute. 2011. Decreto Legislativo 2011/126. Attuazione della direttiva 2008/119/CE che stabilisce le norme minime per la protezione dei vitelli. Gazzetta Ufficiale no. 180 del 4-8-2011. Ministero della Salute, Rome, Italy.

Nombekela, S. W., M. R. Murphy, H. W. Gonyou, and J. I. Marden. 1994. Dietary preferences in early lactation cows as affected by primary tastes and some common feed flavors. J. Dairy Sci 77:2393-2399.

Prevedello, P., M. Brscic, E. Schiavon, G. Cozzi, and F. Gottardo. 2012. Effects of the provision of large amounts of solid feeds to veal calves on growth and slaughter performance and intravitam and postmortem welfare indicators. J. Anim. Sci. 90:3538-3546.

Reece, W. O., and D. K. Hotchkiss. 1987. Blood studies and performance among calves reared by different methods. J. Dairy Sci 70:1601-1611.

Suárez, B. J., C. G. van Reenen, W. J. J. Gerrits, N. Stockhofe, A. M. van Vuuren, and J. Dijkstra. 2006. Effects of supplementing concentrates differing in carbohydrate composition in veal calf diets: II. Rumen development. J. Dairy Sci. 89:4376-4386.

Van Soest, P. J. 1991. Function of the ruminant forestomach. Pages 230-252 in Nutritional Ecology of the Ruminant. 2nd ed. Cornell University Press, Ithaca, NY.

Van Soest, P. J., J. B. Robertson, and B. A. Lewis. 1991. Methods for dietary fiber, neutral detergent fiber, and nonstarch polysaccharides in relation to animal nutrition. J. Dairy Sci. 74:3583-3597.

West, H. J. 1997. Clinical and pathological studies in cattle with hepatic disease. Vet. Res. Commun. 21:169-185.

Zinn, R. A., R. Barrajas, M. Montano, and R. A. Ware. 2003. Influence of dietary urea level on digestive function and growth performance of cattle fed steam-flaked barley-based finishing diets. J. Anim. Sci. 81:2383-2389. 